\title{
Reconhecimento e contagem automáticos de cianobactérias em água bruta de reservatórios da região de Curitiba
}

\author{
Geisla de Albuquerque Melo Laskoski ${ }^{1}$, Antonio Carlos Sobieranski ${ }^{2}$, Thelma \\ Alvim Veiga Ludwig ${ }^{1}$, Lucas Ferrari de Oliveira ${ }^{1}$ \\ ${ }^{1}$ Universidade Federal do Paraná - UFPR \\ Rua Cel. Francisco Heráclito dos Santos, 100 - Centro Politécnico - Curitiba, Paraná \\ ${ }^{2}$ Universidade Federal de Santa Catarina - UFSC \\ Rodovia Governador Jorge Lacerda, 3201 - Bloco B - Araranguá, Santa Catarina \\ geisla@ufpr.br, a.sobieranski@ufsc.br, veigal3ufpr@gmail.com, \\ lferrarieinf.ufpr.br
}

\begin{abstract}
Cyanobacteria are organisms that can occur in reservoirs and springs. Some species can produce harmful toxins by contact or ingestion and may even cause death. The law requires periodic analyzes of water intended for the use of the population to monitor and control their quality. The process of identification and counting of cyanobacteria cells is costly and manual. Artificial intelligence is active in problem solving, and convolutional neural networks are the state of the art in recognition of images and objects. It is proposed to develop an automatic method for identification and counting cyanobacteria cells. Tests have demonstrated the feasibility of the proposal as well as pointed improvements to be made.
\end{abstract}

Resumo. Cianobactérias são organismos que podem ocorrer em reservatórios e mananciais. Algumas espécies podem produzir toxinas, nocivas por contato ou ingestão, podendo causar até morte. A lei exige análises periódicas da água destinada à população, para monitorar e controlar a qualidade. $O$ processo de identificação e contagem das células de cianobactérias é custoso e manual. A inteligência artificial é atuante na resolução de problemas, e as redes neurais convolucionais são o estado da arte no reconhecimento de imagens e objetos. Propõe-se desenvolver um método automático para a identificação e contagem de células de cianobactérias. Testes demonstraram a factibilidade da proposta, bem como apontaram melhorias a serem feitas.

\section{Introdução}

A eutrofização é o enriquecimento dos corpos d'água com nutrientes, por processos naturais ou causados pelo homem [Esteves 1998]. Um ambiente eutrófico possui altas quantidades de nutrientes, o que facilita as florações de algas, e também de cianobactérias.

As cianobactérias são organismos também conhecidos como algas azuis. Elas não têm membrana nuclear (procariontes) e apresentam sistema fotossintetizante semelhante ao das algas. Elas podem se apresentar de forma unicelular ou filamentosa, formando colônias de filamentos ramificados ou irregulares. As células individuais 
isoladas podem formar uma nova colônia. Em floração, há alteração da cor, odor e sabor da água, e formação de espuma esverdeada [Duy et al 2000].

As cianobactérias de água doce possuem a capacidade de desenvolver toxinas em larga escala. Segundo Duy et al (2000), dos cerca de 50 gêneros das cianobactérias de água doce, pelo menos sete (Anabaena, Aphanizomenon, Coelosphaerium, Gloetrichia, Microcystis, Nodulária e Nostoc) contém espécies potencialmente tóxicas.

O contato direto com a água contaminada com cianotoxinas pode causar irritação na pele, olhos e ouvidos, erupções, inchaço nos lábios, dor de garganta, inflamações nos seios da face e asma. Já se ingerida a água contaminada, podem ocorrer náuseas, vômitos, dores abdominais, diarreias, complicações no fígado e fraqueza muscular. Não é indicado utilizar a água para cozimento ou manuseio de alimentos, bem como não se deve comer pescados de águas contaminadas [Copasa 2019].

Em 1996, 61 pessoas morreram na cidade de Caruaru, em Pernambuco, no caso que ficou conhecido como a "Tragédia da Hemodiálise". Os pacientes de uma clínica de hemodiálise foram submetidos às máquinas que filtram o sangue, processo que utiliza água para esta filtragem. A água utilizada estava contaminada com cianobactérias, com a toxina microcystina LR. Estudos indicaram que o nível de água estava baixo, então a cianobactéria se multiplicou gerando altos níveis de cianotoxina [G1 2016].

Atualmente, a Sanepar, empresa de saneamento responsável pelo tratamento de água e esgoto do Paraná, segue as normas da Cetesb (Companhia Ambiental do Estado de São Paulo) no que diz respeito ao monitoramento das cianobactérias, que tem por base a portaria 2914/2011 do Ministério da Saúde. Assim, é considerada ocorrência de floração quando se ultrapassa 10.000 células por $\mathrm{ml}$. A portaria obriga o monitoramento mensal nos pontos de captação de água nos mananciais de abastecimento, quando o número de células de cianobactérias não exceder 10.000 células por $\mathrm{ml}$, e semanalmente quando exceder esse valor. Também exige a análise semanal de cianotoxinas quando o valor exceder 20.000 células por $\mathrm{ml}$ no ponto de captação [Cetesb 2013].

O método de análise atual é um processo custoso. Consiste em coletar amostras de água bruta, colocá-las em uma câmara cilíndrica de utermohl com capacidade de $10 \mathrm{ml}$, posteriormente, no microscópio, escolhe-se um transecto da amostra, isto é, uma faixa em formato de cruz, e então é feita a análise manualmente, para identificação e contagem, nesta parcela da amostra. A análise a nível de espécie é considerada não trivial, e pode-se facilmente passar de 1000 células apenas nos transectos das amostras.

A inteligência artificial (IA) é uma área da computação consolidada, amplamente utilizada na resolução de problemas reais. As Redes Neurais Convolucionais, representam uma técnica de aprendizado de máquina onde a extração de características é aprendida automaticamente a partir do dado bruto. As redes neurais convolucionais representam o estado da arte no reconhecimento de imagens e objetos [Lecun et al 2015], e por esta razão, foram escolhidas para o desenvolvimento do estudo proposto.

O objetivo deste trabalho é realizar a identificação e contagem de células de cianobactérias Microcystis aeruginosa e Cylindrospermopsis raciborskii (abundantes na região de Curitiba), em água bruta de reservatórios, de forma automática, utilizando imagens digitais e inteligência artificial. Com isto, pode-se examinar a amostra inteira, 
aumentar a precisão do método atual, bem como sua periodicidade, o que auxilia diretamente no controle e manejo da qualidade da água que a população usufrui.

\section{Trabalhos Relacionados}

$\mathrm{Na}$ fase de levantamento de literatura, foram encontrados três trabalhos que chamaram atenção. O primeiro deles, de Gandola et al (2016), apresentou um software que faz o reconhecimento de 5 gêneros filamentosos de cianobactérias, utilizando processamento de imagens e indicadores de padrões em 100 imagens. Foi considerado eficaz. Já o segundo trabalho, os autores Zeder et al (2009) fizeram a medição e quantificação de filamentos da cianobactéria Planktothrix. Consideram eficaz, exceto quando o filamento era ramificado. Por fim, o trabalho que mais chamou a atenção, foi o de Mosleh et al (2012). Os autores fizeram um estudo preliminar para desenvolver um método que reconheça cinco gêneros de cianobactérias, incluindo a Microcystis. Em seus primeiros testes, conseguiram 93\% de acerto para 100 imagens. Considera-se este último trabalho como sendo o que mais pode colaborar com o seguimento do estudo aqui proposto.

\section{Materiais e Métodos}

Para alcançar o objetivo esperado, o trabalho tem as principais fases: aquisição de imagens, processamento das imagens, identificação das espécies e contagem das células. Inicialmente, está sendo trabalhado apenas com a espécie Microcystis aeruginosa.

A aquisição de imagens iniciou-se com as coletas de água bruta nos reservatórios de abastecimento de água da região de Curitiba, onde havia floração. As amostras foram armazenadas em um vidro de âmbar com lugol (solução para fixação e conservação). Posteriormente foram preparadas lâminas de microscópio, ou seja, menor volume de água, para melhor precisão do método. As lâminas foram analisadas e fotografadas em resolução 1360x1024 pixels, em um microscópio Olympus, com aumento de 100x. Buscou-se pela cianobactéria Microcystis aeruginosa e por fitoplâncton em geral.

O processamento das imagens resultantes da aquisição deu-se com a utilização da ferramenta de aprendizado profundo chamada TensorFlow ObjectDetection API, para detecção de objetos em imagens. Para sua utilização, foi necessário realizar a segmentação das imagens adquiridas, rotulando imagem por imagem, selecionando exatamente o espaço ocupado pela cianobactéria. Esta segmentação foi realizada com o auxílio da ferramenta LabelImg. O arquivo resultante é um .xml, logo, em seguida foi feita a conversão para .csv, e posteriormente transformado em TFRecords, extensão aceita para o treinamento no ObjectDetection API. O modelo usado para o treinamento foi o ssd_mobilenet_v1_coco, com uma classe, a "Microcystis aeruginosa". Foi reservada uma parte das imagens para realizar a validação posterior. Foram utilizados mil passos para o treinamento, com uma taxa de aprendizado de 0.004 . O treinamento foi feito via prompt de comando, na linguagem de programação Python.

$\mathrm{Na}$ contagem das células, os estudos se deram sobre um modelo matemático de detecção de formas, especial para círculos, a Transformada de Hough, pois as células de Microcystis são circulares (4-6 $\mu \mathrm{m}$ de diâmetro). Esta etapa deu-se utilizando o método implementado da biblioteca de processamento de imagens $O p e n C v$, e ocorre com as seguintes etapas: carrega a imagem, suaviza para reduzir ruídos, aplica o método HoughCircles Transformation, e então desenha os círculos encontrados na imagem. 


\section{Resultados}

Obteve-se aproximadamente quatro mil imagens, metade contendo Microcystis e metade de fitoplâncton em geral. Pode-se observar na Figura 1 uma imagem da cianobactéria Microcystis aeruginosa, bem como do fitoplâncton das amostras, na Figura 2.

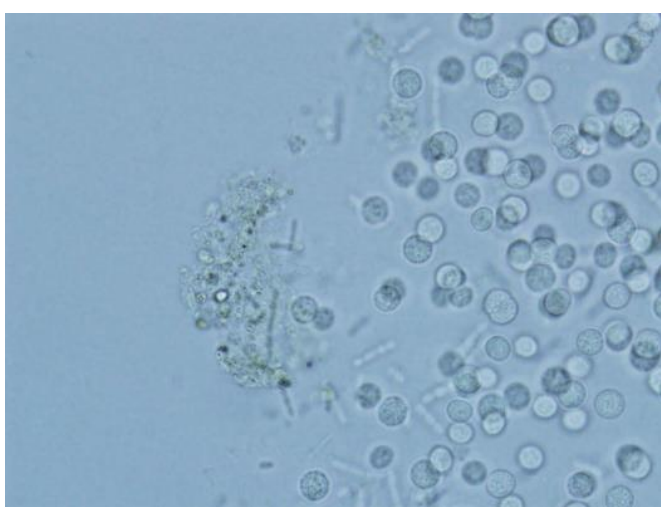

Figura 1. Microcystis aeruginosa

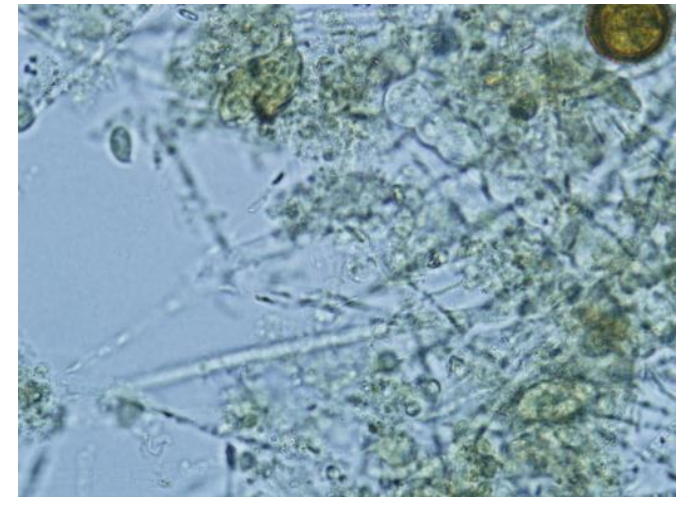

Figura 2. Organismos do Fitoplâncton

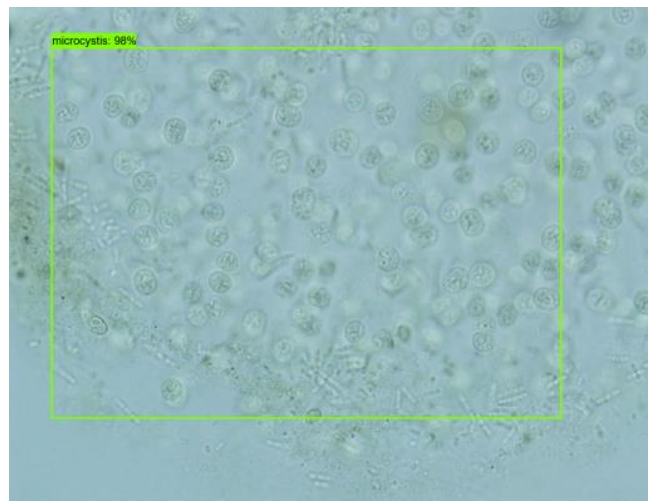

Figura 3. Detecção com acurácia de $98 \%$ 


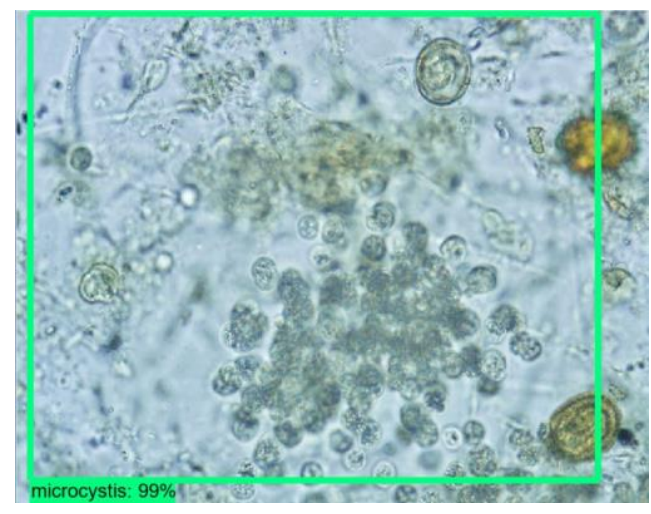

Figura 4. Detecção com acurácia de 99\%

Quanto à identificação da cianobactéria, foram obtidos resultados primários satisfatórios. A Figura 3 mostra uma acurácia de $98 \%$ na detecção de Microcystis aeruginosa, predominante na imagem, e na Figura 4, de 99\%, quando em meio ao fitoplâncton. Isto significa que o modelo predisse que há $98 \%$ e $99 \%$, respectivamente, de certeza que a região demarcada corresponde ao objeto procurado.

Em detecção de objetos, existem outras métricas para avaliar a acurácia, entre elas a IoU (Intersection over Union), que é a intersecção entre o retângulo que representa o objeto, com o retângulo que o modelo predisse. Matematicamente, é a área de sobreposição dividida pela área de união (junção da área verdadeira mais a área predita). Uma IoU acima de 0,5 é considerada uma boa predição. Nos testes, a IoU se manteve entre 0,5 a 0,95 , mais frequentemente próximo de 0,5 .

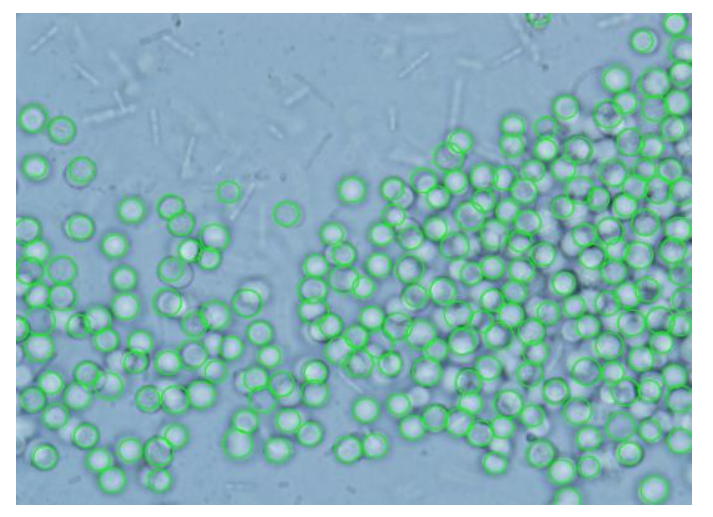

Figura 5. Células detectadas para contagem

A Figura 5 apresenta os desenhos dos círculos sobre as células detectadas.

\section{Discussão}

Na fase de detecção da Microcystis aeruginosa, embora o modelo tenha predito com alta acurácia, houve uma perda de 5,4 no treinamento. Em aprendizado de máquina, este é um erro alto, podendo comprometer o desempenho das predições, e precisa ser reduzido para assegurar a estabilidade. Observa-se também que o método deixa células de fora do retângulo. Estas questões serão melhoradas mediante modificações no treinamento, empiricamente. A IoU próxima do limite inferior para boas predições $(0,5)$, também representa um fator a ser melhorado. 
Quanto à contagem, observam-se falsos negativos e falsos positivos na detecção celular. As duas situações podem causar problemas, negativando uma amostra contaminada, ou positivando uma não contaminada. Outros métodos serão testados, incluindo o de segmentação de células, que independe da forma, considerando que a Cylindrospermopsis é filamentosa. Após isto, se dará a contagem das células detectadas.

\section{Conclusão}

Pode-se concluir que a proposta é factível. Foram obtidos resultados preliminares satisfatórios. Os testes explicitaram melhorias a serem realizadas nos métodos.

O trabalho irá otimizar o tempo de análise, contribuindo para a maior periodicidade. Será também mais preciso que o método atual, substituindo a contagem apenas de um transecto superficial da câmara de $10 \mathrm{ml}$, pela verificação de toda a amostra em lâminas. Será testado em ambiente real, e trará benefícios para a sociedade.

Como trabalhos futuros, ocorrerá a adaptação para outras cianobactérias tóxicas. De mesmo modo, a aplicação terá uma versão embarcada para dispositivos móveis.

\section{Referências}

Cetesb. (2019) "Manual de cianobactérias planctônicas:Legistação, orientações para o monitoramento e aspectos ambientais", São Paulo, http://cetesb.sp.gov.br/laboratori os/wp-content/uploads/sites/24/2015/01/manual-cianobacterias-2013.pdf, Janeiro.

Copasa. (2019) Copasa Orienta - Cianobactérias: o perigo das algas azuis. Saneamento, tratamento e abastecimento de água. Programa Chuá: Educação Sanitária e Ambiental da Copasa, http://www.copasa.com.br/wps/wcm/connect/771d71f8-d24f4cdb-abf8-e3461660d5f6/COPASA_Agua.pdf?MOD=AJPERES, Janeiro.

Gandola E., Antonioli M., Traficante A., Franceschini S., Scardi M., Congestri R. (2016) "ACQUA: Automated Cyanobacterial Quantification Algorithm for toxic filamentous genera using spline curves, pattern recognition and machine learning." J. Microbiol. Methods. 124:48-56.

Duy, T. N., et al. (2000) "Toxicology and risk assessment of freshwater cyanobacterial (blue-green algal) toxins in water." In: Review of Environmental and Contamination and Toxicology, 163: 113-186.

Esteves, F. A. (1998) "Fundamentos de Limnologia”. Ed. Interciência, 2a ed., RJ, 602 p.

G1. (2016) "Tragédia da Hemodiálise que deixou quase 60 mortos completa 20 anos", Recife, $\quad$ http://g1.globo.com/pe/caruaru-regiao/noticia/2016/02/tragedia-dahemodialise-que-deixou-quase-60-mortos-completa-20-anos.html.

Lecun, Y., Bengio Y., Hinton. G. (2015) “Deep Learning”. Nature, v521, p436-444.

Mosleh, M. A. A., Manssor, H., Malek, S., Milow, P., Salleh, A. (2012) “A preliminary study on automated freshwater algae recognition and classification system." BMC Informatics 13 (Suppl 17), S25.

Zeder, M., S. Peter, T. Shabarova, J. Pernthaler. (2009) "A small population of planktonic Flavobacteria with disproportionally high growth during the spring phytoplankton bloom in a prealpine lake." Environ. Microbiol. 